${ }^{1}$ DDS, MDS student, Department of Orthodontics, Graduate Program in Orthodontics, University of Araras UNIARARAS, Araras, SP, Brazil.

${ }^{2}$ DDS, MDS, PhD, Associated Researcher, Department of Restorative Dentistry, Dental Materials Division, Piracicaba Dental School, University of Campinas UNICAMP, Piracicaba, SP, Brazil.

${ }^{3}$ DDS, MDS, PhD, Professor Department of Restorative Dentistry, Dental Materials Division, Piracicaba Dental School, University of Campinas - UNICAMP, Piracicaba, SP, Brazil.

${ }^{4}$ DDS, MDS, PhD, Professor, Institute of Higher Education, FAIPE, Cuiaba, MT, Brazil.

${ }^{5}$ DDS, MDS, PhD, Professor, Department of Restorative Dentistry, Dental Materials Division, Piracicaba Dental School, University of Campinas - UNICAMP, Piracicaba, SP, Brazil.

${ }^{6}$ DDS, MDS, PhD, Professor,

Department of Orthodontics, Graduate Program in Orthodontics, University of Araras - UNIARARAS, Araras, SP, Brazil.

*Corresponding author: Department of Orthodontics, Graduate Program in Orthodontics, University of Araras - UNIARARAS. Av. Dr. Maximiliano Baruto, 500 - Jd Universitário, Araras, SP, Brasil, CEP: 13607-339, +55 19 3543-1423. e-mail:ortodontiavedovello@gmail.com

Received: April 13, 2017

Accepted: August 14, 2017

\section{Influence of adhesive and bonding material on the bond strength of bracket to bovine tooth}

\author{
Bruna Lorena dos Santos Oliveira ${ }^{1 *}$, \\ Ana Rosa Costa ${ }^{2}$, Américo Bortolazzo Correr ${ }^{3}$, \\ Marcus Vinicius Crepaldi ${ }^{4}$, Lourenço Correr-Sobrinho ${ }^{5}$, \\ Julio Cesar Bento dos Santos ${ }^{6}$
}

Aim: To evaluate, in vitro, the effect of adhesive and bonding materials on the shear bond strength (SBS) of metallic brackets bonded to bovine teeth. Methods: Bovine teeth were embedded with acrylic resin, etched with $35 \%$ phosphoric acid for $20 \mathrm{~s}$, rinsed, dried for $20 \mathrm{~s}$ and divided into 8 groups $(n=20)$, according to the bonding materials and adhesive: Groups 1 and 5 - Transbond XT; Groups 2 and 6 - Fill Magic; Groups 3 and 7 - Biofix; and, Groups 4 and 8 - Orthocem. One layer of adhesive $3 \mathrm{M}$ Unitek (Group 1), and one layer of Single Bond Universal Adhesive (Groups 2, 3 and 4) were applied and light-cured with LED for $10 \mathrm{~s}$. Brackets were bonded to the buccal surface with four bonding materials and light-cured with LED for $40 \mathrm{~s}$. SBS was carried out after $24 \mathrm{~h}$ and thermocycling $\left(7,000\right.$ cycles $\left.-5^{\circ} / 55^{\circ} \mathrm{C}\right)$. Data were submitted to two way ANOVA and Tukey's post hoc test $(\alpha=0.05)$. The Adhesive Remaining Index (ARI) was evaluated at $8 x$. Results: The adhesive was effective in increasing the SBS for all bonding materials $(p<0.05)$. Significant difference $(p<0.05)$ on the SBS was observed between bonding materials with or without adhesive. The ARI showed a predominance of scores 0 for all groups. Conclusions: The adhesive improved significantly the SBS of the brackets to teeth. Different SBS values occurred among the bonding materials. ARI index showed predominance of score 0 for all groups.

Keywords: Shear Strength. Orthodontic Brackets. Adhesives. 


\section{Introduction}

The bracket bonding in teeth for mounting orthodontic appliances was one of the most significant advances in orthodontics. The bonding system has been based on the acid-etching technique'. The acid etching allowed improvement in the bond between the bracket and the tooth, enabling the perfectioning of direct fixation techniques of orthodontic appliances to teeth, with the advantage of technical simplification, reduced chair time, more comfort to the patient, better appearance, and less aggression to periodontal tissues².

After the acid etching of enamel, bonding systems have been used to promote increased durability and longevity for orthodontic brackets. The bonding procedure is based on clinical adhesive steps, as etch-and-rinse, self-etching, and self-adhesive ${ }^{3,4}$. Conventional adhesive associates pretreatment of the tooth with an etched-and-rinse or self-etching adhesive. The adhesive penetrates the etched enamel, in order to increase the bond strength between the tooth and the composite resin ${ }^{5}$.

The light-activated composite resins are used to attach orthodontic brackets to the teeth 6 . The composite resins are densely loaded with reinforcing filler particles for strength and wear resistance ${ }^{7}$. The advantage of light-activated composite resins is that the clinician has time to place the brackets in the position, may remove excess material before the light activation ${ }^{8}$, and support adequately the loads applied during orthodontic treatment resulting from chewing 9 . However, failures with composite resins can occur and has been attribute to humidity contamination ${ }^{10}$ or incomplete polymerization when considering the light exposure time or limited depth polymerization $^{11}$, which changes with the light penetration into the material ${ }^{12}$.

Recently, some composites resins have been applied for orthodontic use by many clinicians immediately after acid etching of enamel without adhesive. According to the manufacturers' instructions, the number of steps during bonding is reduced, decreased chair time for patients and less contamination during bonding procedures. However, a study showed that the adhesive promoted a significant effect on the $\mathrm{SBS}^{13}$. However, the literature is still not conclusive regarding the use of adhesive and bonding materials on the bond strength between orthodontic brackets and teeth.

Therefore, the aim of this study was to evaluate the effects of adhesive and bonding materials on the SBS of metallic brackets bonded to bovine teeth. The hypotheses tested were as follows: 1) The adhesive application would not influence the SBS; 2) no significant difference would occur between the bonding materials.

\section{Material and methods}

\section{Preparation of the specimens and light-curing procedures}

Bovine mandibular incisors teeth were embedded in rigid polyvinyl chloride tubes (Tigre, Joinvile, SC, Brazil) with autopolymerizing acrylic resin (Classico Dental Products, Sao Paulo, SP, Brazil). The buccal surface of the teeth were parallel to the tube height, with the cementoenamel junction located approximately $3 \mathrm{~mm}$ above the 
acrylic resin. The buccal surface of the teeth was cleaned with pumice-water slurry (S.S. White, Petropolis, RJ, Brazil) using a rubber cup (KG Sorensen, Cotia, SP, Brazil) for $20 \mathrm{~s}$, rinsed with air-water spray for $20 \mathrm{~s}$ and dried with air for $20 \mathrm{~s}$. The rubber cup was replaced after each five teeth.

The middle third of the buccal surface of the one hundred sixty bovine incisors were etched using 35\% phosphoric acid gel (Ultrandent, South Jordan, UT, USA) for $20 \mathrm{~s}$, rinsed with air-water spray for $20 \mathrm{~s}$ and dried with air for $20 \mathrm{~s}$. After, the teeth were divided into 8 groups ( $n=20)$ according to bonding materials and adhesive: Groups 1 and 5 - Transbond XT (3M Unitek, Morovia, Califórnia - USA); Groups 2 and 6 - Fill Magic (Vigodent, Rio de Janeiro, RJ, BR); Groups 3 and 7 - Biofix (Biodinamics, Ibipora- PR, BR); and, Groups 4 and 8 - Orthocem (FGM Orthodontics Products, Joinville, SC,BR).

One layer of a light cured adhesive primer (3M Unitek, Monrovia, CA, USA - Group 1) and one layer of Single Bond Universal Adhesive (3M ESPE, St. Paul, MN, USA Groups 2, 3 and 4) were applied on the etched area of buccal surface of the teeth and exposed a blue LED (Radii-cal, SDI Limited, Bayswater, Victoria, Australian) for $20 \mathrm{~s}$ with an irradiance of $1,200 \mathrm{~mW} / \mathrm{cm}^{2}$ measured by Curing Radiometer Model 100 (Demetron Research Corporation, Danbury, CT). Stainless steel standard premolar brackets (Abzil, 3M do Brazil, Sao Jose do Rio Preto, SP, Brazil) were positioned and firmly bonded of each tooth with Transbond XT (3M Unitek), Fill Magic (Vigodent), Biofix (Biodinamica) or Orthocem (FGM) light-cured bonding materials, following the manufacturers' instructions. Excess bonding resin was removed with microbrush. Light-activation was carried out with four exposures on each side of the bracket with total exposure time of $40 \mathrm{~s}$, using a blue LED (Radii-cal).

\section{Storage and Bonding Testing}

After the bonding procedures, all samples were stored in deionized water at $37^{\circ} \mathrm{C}$ for $24 \mathrm{~h}$. Twenty brackets were bonded in each group, totalizing 160 bonded brackets. After this period, all samples were subjected to a thermal cycles regimen in a thermal cycling (MSCT 3; Marnucci ME, Sao Carlos, SP, Brazil) with deionized water between $5{ }^{\circ} \mathrm{C}$ and $55^{\circ} \mathrm{C}$ (dwell time of $30 \mathrm{~s}$ ) and transfer time of $10 \mathrm{~s}$ between baths.

\section{Shear Bond Strength Testing}

After thermal cycling, a mounting jig was used to align the tooth-bracket interface parallel to the testing device and SBS was performed in a universal mechanical testing machine (Model 4411; Instron, Canton, MA, USA) with a knife-edged rod at a crosshead speed of $1.0 \mathrm{~mm} / \mathrm{min}$ until failure. The SBS data were calculated in MPa and submitted to two-way ANOVA and Tukey's post hoc test $(\alpha=0.05)$.

\section{Failure Analysis}

After debonding, the bracket and tooth surfaces were observed under optical microscopy (Olympus Corp, Tokyo, Japan) at 8x magnification. The Adhesive Remaining Index (ARI) was used to classify the failure modes ${ }^{14}$ as follows: Score 0: indicated that no bonding resin remained on the tooth; Score 1 : indicated that less than half of the bonding resin remained on the tooth; Score 2: indicated that more than half the 
bonding resin remained on the tooth; and Score 3: indicated that all bonding resin remained on the tooth, with a clear impression of the bracket mesh.

\section{Results}

Table 1 shows the mean values of SBS. Significant differences between the bonding materials $(p<0.00001)$ and adhesive $(p<0.00001)$ were detected. The interaction between bonding materials and adhesive factors $(p<0.0003)$ were also significant. The use of adhesive had a significant effect on SBS for all bonding materials.

Table 1. Mean shear bond strength values (SD) in MPa.

\begin{tabular}{lcl}
\hline \multirow{2}{*}{ Bonding Material } & \multicolumn{2}{c}{ Adhesive } \\
\cline { 2 - 3 } & With & Without \\
\hline Transbond XT & $10.3(1.2) \mathrm{a}, \mathrm{A}$ & $6.9(1.3) \mathrm{a}, \mathrm{B}$ \\
\hline Fill Magic & $9.0(0.8) \mathrm{b}, \mathrm{A}$ & $5.0(1.0) \mathrm{b}, \mathrm{B}$ \\
\hline Biofix & $8.3(1.4) \mathrm{bc}, \mathrm{A}$ & $4.3(0.7) \mathrm{b}, \mathrm{B}$ \\
\hline Orthocem & $7.8(1.3) \mathrm{c}, \mathrm{A}$ & $4.2(0.8) \mathrm{b}, \mathrm{B}$ \\
\hline
\end{tabular}

Different capital letters in each row indicate significant difference for adhesive, and different small letters in each column indicate significant difference for bonding materials $(p<0.05)$.

The Transbond XT showed SBS statistically higher than the other bonding materials $(p<0.05)$, and the Orthocem had the lowest SBS values $(p<0.05)$ when adhesive was used. For the group without adhesive, the Transbond XT showed SBS statistically higher than Fill Magic, Biofix and Orthocem $(p<0.05)$. No statistically difference was found among Fill Magic, Biofix and Orthocem $(p>0.05)$

Figure 1 shows the results for ARI. A predominance of score 0 was observed for all groups.

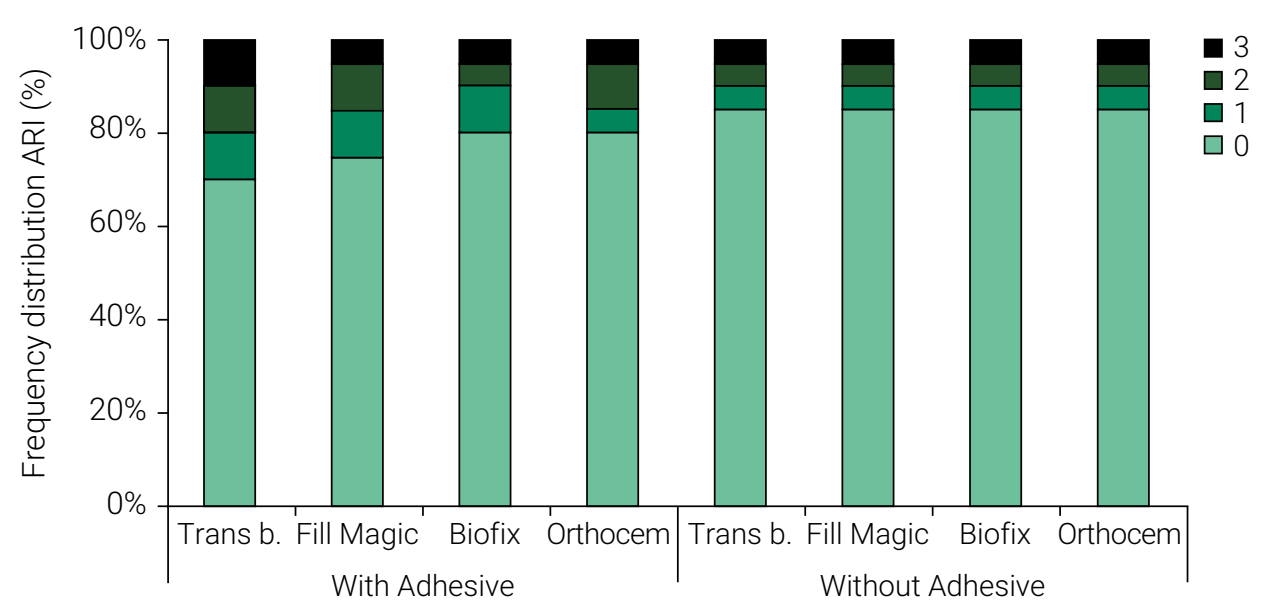

Figure 1. ARI scores after debonding of brackets. 


\section{Discussion}

The first hypothesis, which stated that the adhesive application do not influence the SBS was rejected. The results showed that significant differences were shown between the groups with adhesive and without adhesive. These results are in line with previous study, which also found significant differences between the groups with and without adhesives ${ }^{13}$. However, a recent study showed that brackets fixed without adhesive presented a debonding rate after 12 months similar to that of brackets fixed with adhesive ${ }^{15,16}$. Other study showed that the penetration of the liquids into narrow capillaries, such as microporosities of etched enamel was influenced by properties of the liquid, such as viscosity and the surface free energy of the capillary wall ${ }^{17}$. Besides, viscosity of composite resin is a parameter that can influence the penetration of restorative resins into enamel conditioned ${ }^{18}$.

In the current study, the data showed significant differences between the bonding materials $(p<0.0001)$. Then, the second hypothesis was rejected. The Transbond XT produced significantly higher SBS than another bonding material for both conditions with or without application of the adhesive. These findings are in agreement with previous studies, which also found significant differences between these bonding materials, when brackets were bonded to enamel surface ${ }^{13,19,20}$. However, other study showed that when the adhesive was not applied, SBS of bonding materials did not differ among themselves, except for Transbond Supreme LV that showed SBS values significantly higher than other bonding materials ${ }^{13}$. Although Transbond XT has a high filler concentration (77 wt\%), it showed SBS values of 6.9 MPa adequate for clinical use. Previous studies showed that the filler concentration may clinically influence the viscosity of bonding materials ${ }^{21}$, but the higher viscosity can not limit the free flow of the resin into the enamel pores and the formation of resin tags ${ }^{22}$. Other studies showed that flowable resins can flow easily into an etched enamel structure adequately and onto a bracket base without need of an intermediate bonding resin, thus an enhance in the level of mechanical properties are expected ${ }^{13}$. Depth of resin penetration into enamel decreases slightly with increasing viscosity ${ }^{23}$. Others studies showed that, when applied to acid-enamel, there are no significant differences between low-viscosity and high-viscosity resins in terms of adaptation and depth of penetration ${ }^{24}$.

Bond strength values between 6 to $8 \mathrm{MPa}$ are adequate for orthodontic applications in oral environment ${ }^{25}$. In this study, SBS values lower than $6 \mathrm{MPa}$ were obtained for Fill Magic, Biofix and Orthocem bonding materials where adhesive was not applied. Although the manufacturers of Fill Magic, Biofix and Orthocem bonding resins do not recommend the use of adhesives, the results of this study showed that the adhesive is necessary to obtain adequate SBS values. Thus, care should be taken by clinicians when adhesive is not used especially when the Fill Magic, Biofix or Orthocem are used because these bonding resins have not been acceptable clinically SBS to resist forces during orthodontic treatment.

The ARI values indicated a predominance of failures with score 0 when no bonding resin on the ceramic surface was observed. This may be clinically advantageous because there is less bonding resin to remove from the bovine teeth after bracket debonding ${ }^{26}$.

It may be concluded that the SBS values for bonding materials were influenced by the adhesives application. Different SBS values occurred among the bonding materials. The IRA index showed predominance of score 0 for all groups. 


\section{References}

1. Buonocore MG. A simple method of increasing the adhesion of acrylic filling materials to enamel surfaces. J Dent Res. 1955 Dec;34(6):849-53.

2. Busato MCA, Busato PMR, Dotto DV, Pedrotti S, Gasparello CR. Evaluation of shear bond strength of backets bonded with different orthodontic resins. Rev Clin Orthodon Dental Press. 2013 Mar-Apr;12(2):94-9.

3. Silami FD, Tonani R, Alandia-Roman CC, Pires-de-Souza Fde C. Influence of Different Types of Resin Luting Agents on Color Stability of Ceramic Laminate Veneers Subjected to Accelerated Artificial Aging. Braz Dent J. 2016 Jan-Feb;27(1):95-100. doi: 10.1590/0103-6440201600348.

4. Lenzi TL, Soares FZ, Raggio DP, Pereira GK, Rocha RO. Dry-bonding Etch-and-Rinse Strategy Improves Bond Longevity of a Universal Adhesive to Sound and Artificially-induced Caries-affected Primary Dentin. J Adhes Dent. 2016 Nov-Dec;18(6):475-82. doi: 10.3290/j.jad.a36670.

5. Antoniazzi BF, Nicoloso GF, Lenzi TL, Soares FZ, Rocha RO. Selective Acid Etching Improves the Bond Strength of Universal Adhesive to Sound and Demineralized Enamel of Primary Teeth. J Adhes Dent. 2016 Jul-Aug;18(4):311-6. doi: 10.3290/j.jad.a36154.

6. BenGassem AA, Georgiou G, Jones SP. Initial and fatigue bond strengths of nanofilled and conventional composite bonding adhesives. J Orthod. 2013 Jun;40(2):137-44. doi: 10.1179/1465313312Y.0000000034.

7. Wang RL, Bao S, Liu FW, Jiang XZ, Zhang QH, Sun B, et al. Wear behavior of light-cured resin composites with bimodal silica nanostructures as fillers. Mater Sci Eng C Mater Biol Appl. 2013 Dec;33(8):4759-66. doi: 10.1016/j.msec.2013.07.039.

8. Costa AR, Correr AB, Puppin-Rontani RM, Vedovello SA, Valdrighi HC, Correr-Sobrinho L, et al. Effects of thermocycling and light source on the bond strength of metallic brackets to bovine teeth. Braz Dent J. 2011 Nov-Dec;22(6):486-9. doi: http://dx.doi.org/10.1590/S0103-64402011000600008.

9. Romano FL, Correr AB, Correr-Sobrinho L, Magnani MB, Ruellas AC. Clinical evaluation of the failure rates of metallic brackets. J Appl Oral Sci. 2012 Mar-Apr;20(2):228-34. doi: http://dx.doi.org/10.1590/S1678-77572012000200018.

10. Roelofs T, Merkens N, Roelofs J, Bronkhorst E, Breuning H. A retrospective survey of the causes of bracket- and tube-bonding failures. Angle Orthod. 2017 Jan;87(1):111-7. doi: 10.2319/021616-136.1.

11. Correr AB, Sinhoreti MA, Sobrinho LC, Tango RN, Schneider LF, Consani S. Effect of the increase of energy density on Knoop hardness of dental composites light-cured by conventional QTH, LED and xenon plasma arc. Braz Dent J. 2005 Sep-Dec;16(3):218-24. doi: http://dx.doi.org/10.1590/S0103-64402005000300009.

12. Dalli'Magro E, Sinhoreti MA, Correr AB, Consani RL, Sicoli EA, Mendoca MJ, et al. Effect of different modes of light modulation on the bond strength and knoop hardness of a dental composite. Braz Dent J. 2008 Oct-Dec;19(4):334-40. doi: http://dx.doi.org/10.1590/S0103-64402008000400009.

13. Albaladejo A, Montero J, Gomez de Diego R, Lopez-Valverde A. Effect of adhesive application prior to bracket bonding with flowable composites. Angle Orthod. 2011 Jul;81(4):716-20 doi: 10.2319/062310-344.1.

14. Artun J, Bergland S. Clinical trials with crystal growth conditioning as an alternative to acid-etch enamel pretreatment. Am J Orthod. 1984 Apr;85(4):333-40.

15. Nandhra SS, Littlewood SJ, Houghton N, Luther F, Prabhu J, Munyombwe T, et al. Do we need primer for orthodontic bonding? A randomized controlled trial. Eur J Orthod. 2015 Apr;37(2):147-55. doi: 10.1093/ejo/cju024.

16. Altmann AS, Degrazia FW, Celeste RK, Leitune VC, Samuel SM, Collares FM. Orthodontic bracket bonding without previous adhesive priming: A meta-regression analysis. Angle Orthod. 2016 May;86(3):391-8. doi: 10.2319/041615-255.1.

17. Newman S. Kinetics of Wetting of Surfaces by Polymers - Capillary Flow. J Colloid and Interface Sci. 1968 Feb;26(2):209-13. doi: 10.1016/0021-9797(68)90313-5. 
18. Asmussen E. Penetration of restorative resins into acid etched enamel. I. Viscosity, surface tension and contact angle of restorative resin monomers. Acta Odontol Scand. 1977 Feb;35(4):175-82.

19. Correr Sobrinho L, Correr GM, Consani S, Sinhoreti MA, Consani RL. [Influence of post-fixation time on shear bond strength of brackets fixed with different materials]. Pesqui Odontol Bras. 2002 Jan-Mar;16(1):43-9. doi: http://dx.doi.org/10.1590/S1517-74912002000100008. Portuguese.

20. Pepe MM, ALucato AS, dos Santos JCB, Tubel CAM, Valdrighi HC, Correr AB. [Shear bond strength to enamel after application of adhesive on the mesh of brackets]. Rev Ortod SPO. 2015 Sep-0ct;48(5):441-5. Portuguese.

21. Collares FM, Klein M, Santos PD, Portella FF, Ogliari F, Leitune VCB, et al. Influence of radiopaque fillers on physicochemical properties of a model epoxy resin-based root canal sealer. J Appl Oral Sci. 2013 Nov-Dec;21(6):533-9. doi: 10.1590/1679-775720130334.

22. Mehrabkhani M, Mazhari F, Sadeghi S, Ebrahimi M. Effects of sealant, viscosity, and bonding agents on microleakage of fissure sealants: An in vitro study. Eur J Dent. 2015 Oct-Dec;9(4):558-63. doi: 10.4103/1305-7456.172631.

23. Asmussen E. Penetration of restorative resins into acid etched enamel. II. Dissolution of entrapped air in restorative resin monomers. Acta Odontol Scand. 1977;35(4):183-91.

24. Pahlavan A, Dennison JB, Charbeneau GT. Penetration of Restorative Resins into Acid-Etched Human Enamel. J Am Dent Assoc. 1976 Dec;93(6):1170-6.

25. Reynolds IR. Composite filling materials as adhesives in orthodontics. Br Dent J 1975 Feb;138(3):83.

26. Costa AR, Correr AB, Puppin-Rontani RM, Vedovello SA, Valdrighi HC, Correr-Sobrinho L, et al. Effect of bonding material, etching time and silane on the bond strength of metallic orthodontic brackets to ceramic. Braz Dent J. 2012 Jul-Aug;23(3):223-7. doi: http://dx.doi.org/10.1590/S0103-64402012000300007. 